\title{
Research on the Effects of Different Listening Process Models in Listening Comprehension and Memory Based on Cognitive Psychology Qiuxia Guo
}

\author{
Nanchang Institute of Science \&Technology, Nanchang 330108, China
}

\begin{abstract}
Keywords: listening comprehension, listening memory, listening process models, listening problems, strategies training.
\end{abstract}

\begin{abstract}
In order to explore the effects of the three main listening process models in English majors' listening comprehension and memory, and find out the problems and the solving strategies they uesd, the present study conducted a 12-week research on 120 sohpomore English majors. By means of pre-test, questionnaire, strategies training courses, post-test and interview, the results showed that: (1) the three listening process models, especially the interactive model, have positive effects on students' listening comprehension and memory competence; (2) the top-down model and the bottom-up model is mutual, they affected and promoted each other; (3) the problems that the students had in the process of listening are similar, and are collected into eight kinds; (4) there are differences in selecting strategies and memorizing key points and details when the students recalled the listening materials.
\end{abstract}

\section{Introduction}

Information processing theory, as one of those theories in cognitive psychology, is concerned with two modes in which people deal with the information they got. One is the bottom-up mode, the other is top-down mode. The importance of the two modes has always been different as task types and the subject's cognitive activities change. And these research achievements have positive repercussions in the field of English listening teaching. Richards (2006) put forward three listening process models: (1) the bottom-up model, aims to divide the text into several discernible parts and process information, according to the linear order "phoneme — word - phrase — sentence — text"; (2) the top-down model, which emphasizes listeners should predict, infer, filtrate or assimilate the input information based on the prior knowledge; (3) the interactive model, comprehensively combines these two models to process information. How is the relationship among different listening process models? What problems do students have under the guidance of different listening process models strategies? What are the differences in the effect of the students' listening comprehension and listening memory by implementing different listening process models?

\section{Research Design}

Subjects: The subjects in this research are 120 sophomore English majors from 5 classes in a university in Jiangxi Province. 30 students are randomly selected as a group, 4 groups in total. The one-way ANOVA statistical analysis of listening performance in the mid-term and final exams in the last semester shows that the subjects as a whole show no difference in listening competence. (mid-term exam: $\mathrm{F}=.031, \mathrm{p}=.984>.05$; final exam: $\mathrm{F}=.079, \mathrm{p}=.977>.05$ ). Previous research have demonstrated that there is no significant differences among students' listening strategies, age and gender so that this research hasn't considered these two factors.

Instruments: Three instruments are used in the research, pre-test and post-test, a questionnaire and an interview. At first, selected a parallel class, which is not chosen as the subjects of this research, to test the listening materials. Then the results of paired-t test show that the students' average scores have no significant differences, which means there is no significant difference in the listening materials of the tests.

Tests. The listening materials of pre-test and post-test, which have been processed according to the experimental requirements, are two pieces of VOA news. The listening tasks contains three parts. The multiple-choice part has 10 items, they are 5 overall questions and 5 questions in detail. One point for 
each, ten points in total. The English summary dictation and recall part aims to examine the students' listening memory competence. The subjects were all come into contact with the listening materials for the first time.

Questionnaire. The questionnaire in this research includes two parts. It is mainly used to analyze the problems the students had in the listening process. The first part is adopted from Goh's famous questionnaire about following items, such as the frequency of the common problems the subjects have in listening, the reliability and validity of the questionnaire. The second part is concerned with other problems the subjects may encounter during the listening process.

Interview. In order to let the subjects express their ideas as clearly as possible, avoid making some language mistakes, the researcher and the participants all spoke Chinese in the interview. The interview was conducted after the tests.

\section{Research Steps}

Pre-test. The listening material of the pre-test is a piece of VOA news (396 words), which takes four minutes eleven seconds, is divided into forty-two semantic units. There are four steps in this test part of the four groups: (1) The researcher explained the purposes, methods and standards for evaluation to the students; (2) For the first play, the students were asked to take notes and complete the ten multiple-choice items in ten minutes; (3) For the second play, the students should also take notes and wrote down the English summary of the listening material in twenty minutes; (4) the students were required to make English summary recall on the day after the test and a week after the test. and according to their memories, the students should try to write down the summary as completely as possible in twenty minutes.

The Strategies Training of Listening Process Models. The subjects all attended the 12-week strategies training courses of listening process models. All the experimental activities were conducted in the regular listening courses, two classes a week. The four groups used the same materials, but teachers implemented different teaching models to them during the experimental teaching process: the control group accepted the traditional model, experimental group 1 adopted the bottom-up model, experimental group 2 used the top-down model and experimental group 3 put the interactive model into effect. The strategies teaching of listening process models of the experimental groups is explicit.

Post-test. The listening material of the post-test is also a piece of VOA news (415 words). It takes four minutes thirty-one seconds, which is divided into forty-seven semantic units. And the steps in the post-test are the same as those in pre-test.

\section{Analysis of Data}

The subjects' scores of the multiple-choice part and the English summary part were used as data in the research. The number of the students who wrote one of the semantic units in each group was regarded as the group's score of this semantic unit. Each semantic unit was bound up with the understanding of the source text, including the theme, content, events, characters, etc. SPSS was used to generate all descriptive statistics and the results of the statistical analysis.

Differences in Listening Comprehension Competence of Different Models. As shown in Table 1 , there is no significant differences in the listening comprehension competence of pre-test $(\mathrm{F}=.032$, $\mathrm{p}=.956>.05)$, however, the differences in the listening comprehension competence of post-test $(\mathrm{F}=135.48, \mathrm{p}=.000<.05)$ are very significant. 
Table 1. The One-way ANOVA Statistical Analysis of Listening Performance Between Pre-test and Post-test (CG: control group, EG: experimental group).

\begin{tabular}{|c|c|c|c|c|c|c|c|c|c|}
\hline \multirow{2}{*}{ Groups } & \multirow{2}{*}{ Persons } & \multicolumn{2}{|c|}{ Mean } & \multicolumn{2}{c|}{ Std. Deviation } & \multicolumn{2}{|c|}{$F$} & \multicolumn{2}{c|}{$\mathrm{p}$} \\
\cline { 3 - 7 } & & pre-t & post-t & pre-t & post-t & pre-t & post-t & pre-t & post-t \\
\hline CG & 30 & 3.65 & 4.22 & 1.183 & .905 & & & & \\
\hline EG1 & 30 & 3.68 & 6.01 & 1.201 & .827 & \multirow{3}{*}{0.032} & 135.4 & .956 & .000 \\
EG2 & 30 & 3.71 & 6.10 & 1.278 & .951 & & 8 & & \\
\hline EG3 & 30 & 3.65 & 8.53 & 1.183 & .796 & & & & \\
\hline
\end{tabular}

The results of the Post-Hoc multiple comparisons between pre-test and post-test (see Table 2) show that the subjects have no significant differences in the pre-test listening performance $(\mathrm{p}>.05)$. As for the post-test listening performance, except the result that there is no significant differences between experimental group 1 and experimental group 2, other groups all have significant differences on each other: the listening performance of experimental group 3 is much higher than other groups $(\mathrm{p}=.000<.05)$; there are very significant differences between experimental group 1 and control group, experimental group 2 and control group $(\mathrm{p}=.000<.05)$.

Table 2. The Post-Hoc Multiple Comparisons of Listening

Performance Between Pre-test and Post-test (CG: control group, EG: experimental group).

\begin{tabular}{|c|c|c|c|c|c|}
\hline \multirow{2}{*}{ Groups } & \multirow{2}{*}{ Groups } & \multicolumn{2}{|c|}{ M. Deviation } & \multicolumn{2}{|c|}{$\mathrm{p}$} \\
\cline { 3 - 6 } & EG1 & Pre-test & Post-test & Pre-test & Post-test \\
\cline { 2 - 6 } & EG2 & -.031 & -1.878 & .904 & .000 \\
\cline { 2 - 6 } & EG3 & .000 & -1.976 & .822 & .000 \\
\hline \multirow{2}{*}{ EG1 } & EG2 & -.031 & -4.254 & .995 & .000 \\
\cline { 2 - 6 } & EG3 & .031 & -2.383 & .904 & .647 \\
\hline EG2 & EG3 & .065 & -2.584 & .804 & .000 \\
\hline
\end{tabular}

On the whole, the strategies training of listening process models plays an important role in promoting the subjects' listening comprehension. The reason why the interactive listening model plays the most effective role among these strategies is that the students can not only master the overall situation through the top-down listening model, but also improve their language skills and process information in detail by applying the bottom-up strategy. Thus, the top-down model and the bottom-up model is mutual and they affect each other. When the students master the strategies of one model, they can fully understand the problems in it. And they can also strengthen their abilities to understand and solve problems in another model. The results of the present research indicate that the students of experimental group 1 improved their capacity to master the overall situation and the students of experimental group 2 enhanced their capacity to understand the problems in detail. In the interview, 25 students of experimental group 1 think that they would seek ways to solve the overall situation, which has proved not that effective. Meanwhile, 27 students of experimental group 2 feel that the effect is not good when they try to find strategies and solutions to the problems in detail.

Differences in Listening Problems and Their Solving Strategies. The results of the questionnaire and the interview indicate the eight problems that the students had in the process of listening, listed in descending order of performance: (1) they can't understand the meanings of the unknown words; (2) they can't identify and recognize the familiar words; (3) they would miss the following sentence when they're thinking about the last sentence; (4) they would easily forget the information they're listening; (5) they can't grasp the key words and critical information; (6) they can get the point of each sentence, but can't comprehend the meaning of the text on the whole; (7) they can't get used to the speaker's accent and intonation; (8) they don't know much about the content in context of culture. 
The results of the interview show that the students would apply the strategies of different models they learned and find specific solutions to these problems they encountered. The students in experimental group 1 significantly improved their abilities to tackle with problems in detail, while the students' abilities to deal with overall problems were significantly enhanced in experimental group 2. What's more, The students in experimental group 3 could solve the problems of the unknown words by using the strategies of the interactive model, but students couldn't comprehend the listening materials well with too many unknown words. 18 students in experimental group 2 and 22 students in experimental group 3 could correctly infer the unknown word meanings by implementing the top-down model, however, too many unknown words would result in huge burdens for the students.

Differences in Listening Memory Competence of Different Models. The criterion of the differences in listening memory competence is the number of the semantic units that the subjects used in the English summary. As can be seen from Table 3, in pre-test, there is no significant differences in summary dictation $(\mathrm{F}=.424, \mathrm{p}=.709>.05)$, and it also reveals no significant difference in summary recall (recall 1: $\mathrm{F}=.755, \mathrm{p}=.512>.05$; recall $2: \mathrm{F}=.613, \mathrm{p}=.578>.05$ ). By comparison, the differences in summary dictation in post-test are very significant $(\mathrm{F}=.424, \mathrm{p}=.709>.05)$, and there are significant differences between summary recall 1 and summary recall 2 .

Table 3. The One-way ANOVA Statistical Analysis of English Summary Performance Between Pre-test and Post-test (CG: control group, EG: experimental group, D: dictation, R: recall).

\begin{tabular}{|c|c|c|c|c|c|c|c|c|c|c|c|c|}
\hline \multirow[b]{2}{*}{$\mathrm{G}$} & \multicolumn{3}{|c|}{ F (pre-test) } & \multicolumn{3}{|c|}{ p (pre-test) } & \multicolumn{3}{|c|}{ F (post-test) } & \multicolumn{3}{|c|}{$\mathrm{p}$ (post-test) } \\
\hline & $\mathrm{D}$ & R1 & R2 & $\mathrm{D}$ & R1 & $\mathrm{R} 2$ & $\mathrm{D}$ & $\mathrm{R} 1$ & $\mathrm{R} 2$ & $\mathrm{D}$ & $\mathrm{R} 1$ & $\mathrm{R} 2$ \\
\hline CG & \multirow{4}{*}{.424} & \multirow{4}{*}{.755} & \multirow{4}{*}{.613} & \multirow{4}{*}{.709} & \multirow{4}{*}{.512} & \multirow{4}{*}{.578} & \multirow{4}{*}{81.795} & \multirow{4}{*}{1.256} & \multirow{4}{*}{2.084} & \multirow{4}{*}{.000} & \multirow{4}{*}{.000} & \multirow{4}{*}{.000} \\
\hline EG1 & & & & & & & & & & & & \\
\hline EG2 & & & & & & & & & & & & \\
\hline EG3 & & & & & & & & & & & & \\
\hline
\end{tabular}

According to the results of the summary dictation in post-test, the three listening models all contribute to the improvement of the students' short-term memory. Furthermore, the results of the interview suggest that: (1) 19 students in experimental group 1 couldn't grasp the overall information because they are too extreme about the those in detail; (2) 20 students in experimental group 2 could get an integrated frame of the content, but couldn't remember the detailed information; (3) 26 students in experimental group 3 could write down the English summary based on the interactive model strategies.

The results of the summary recall in post-test show that the interactive model plays the most effective role in students' long-term memory. In addition, the results of the interview reveal that: (1) the students in experimental group 1 could basically recall the detailed information in the dictation, but couldn't apply the top-down strategies to other information; (2) the subjects in experimental group 2 could recall the overall information, but the detailed content would have discrepancies with the original; (3) the subjects in experimental group 3 could recall more detailed contents according to the overall information.

\section{Conclusion}

Listening is a complex process, which acquires listeners constantly process and input the information according to their own linguistic and extra-linguistic knowledge. Likewise, the strategies teaching of listening process models is the process that cultivate and improve the students' short-term memory abilities and long-term memory abilities, which also stresses the importance of linguistic and extra-linguistic knowledge. This research explores the relationship among different listening process models and their differences in listening comprehension competence and listening memory competence. Therefore, teachers should guide the students how to determine the contents on the basis of memory's characteristics, and help the students reduce their memory burdens so as to convert their short-term memories into long-term memories efficiently during the listening teaching process. Like 
all the studies, the present research also has some limitations and further investigation is still needed.

\section{References}

[1] C. Zhu. Psychology in foreign language teaching [M]. Shanghai: Shanghai Foreign Language Education Press, 1994.

[2] D. L. Guo \& B. Y. Zhang. Cognitive psychology [M]. Hangzhou: Zhejiang Foreign Language Education Press, 2004.

[3] Field J. Finding one's way in the fog: Listening strategies and second language learners [J]. Modern English Teacher, 2001.

[4] Ghoneim N. M. M. The listening comprehension strategies used by college students to cope with aural problems in EFL classes: An analytical study [J]. English Language Teaching, 2013, (6): 100-112.

[5] Jannejad. M \& Shokouhi. H. The effects of controlled language processing on listening comprehension and recall [J]. English Language Teaching, 2012, (9): 155-165.

[6] J. F. Xu \& B. B. Li. College students' listening styles and their influences on listening comprehension [J]. Foreign Language Teaching and Research, 2009, (3): 186-192.

[7] L. He. Listening probelms and strategies in college English teaching [J]. Journal of Anqing Normal University, 2005, (2): 118-121.

[8] L. Yang. English learning strategies training-take listening course as a study case [M]. Chengdu University of Technology, 2007.

[9] Q. Guan. Cross language learning psychological assessment-Evidence from Chinese and English listening motivation and listening level. Foreign language teaching theory and practice, 2013, (1): 14-18.

[10] Q. Yang. The exploration and practice of College English listening teaching [J]. Foreign Language World, 2002, (2): 58-60.

[11] Richards. J. Second language listening: theory and practice [M]. Cambridge: Cambridge University Press, 2006. 